\title{
Establishing percentiles for blood pressure based on absolute height for children and adolescents
}

\author{
Marco Cossio-Bolaños ${ }^{1}$, Rubén Vidal-Espinoza ${ }^{2}$, Felipe Castelli Correia de Campos ${ }^{3}$, José Sulla-Torres ${ }^{4}$, \\ Wilbert Cossio-Bolaños ${ }^{5}$ Cynthia Lee Andruske ${ }^{6}$, Camilo Urra Albornoz ${ }^{7}$ and Rossana Gómez Campos ${ }^{*}$
}

\begin{abstract}
Background: Evaluating blood pressure (BP) is one element for diagnosing and preventing disease in student populations. The objectives of this research were to (a) identify the range of height for measuring BP adjusted for student populations and (b) propose percentiles for evaluating BP based on height.

Methods: A cross-sectional study was carried out with 3,013 students. Weight, height, and diastolic (DBP) and systolic (SBP) blood pressure were evaluated. Body Mass Index (BMI) was calculated. Height ranges of 5 and $10 \mathrm{~cm}$ were generated.

Results: $R^{2}$ values for height ranges of $5 \mathrm{~cm}$ consisted of [normotensive: $\mathrm{DBP}\left(R^{2}=10\right.$ to $\left.13 \%\right)$ and $\mathrm{SBP}\left(\mathrm{R}^{2}=14\right.$ to $20 \%)$, and for hypertensive: $\operatorname{DBP}\left(R^{2}=0.07\right.$ to $\left.15 \%\right)$ and for $\operatorname{SBP}\left(R^{2}=29\right.$ to $\left.32 \%\right)$ ]. For height ranges of $10 \mathrm{~cm}$, values included: [normotensive: $\mathrm{DBP}\left(\mathrm{R}^{2}=10\right.$ to $\left.15 \%\right)$, and SBP $\left(R^{2}=15\right.$ to $\left.21 \%\right)$ and for hypertensive: $\mathrm{DBP}\left(\mathrm{R}^{2}=0.07\right.$ to $16 \%$ ) and SBP ( $R^{2}=29$ to $\left.35 \%\right)$. For $5 \mathrm{~cm}$ height ranges, diferences occurred between both sexes for DBP (in 5 height ranges from 123 to $148 \mathrm{~cm}$ and 158 to $168 \mathrm{~cm}$ ) and for the SBP (in 6 height ranges from 128 to $148 \mathrm{~cm}$ and from 158 to $168 \mathrm{~cm}$ ). In the $10 \mathrm{~cm}$ categories, diferences appeared in DBP (from 138 to $148 \mathrm{~cm}$ ) and in the SBP (from 158 to $168 \mathrm{~cm}$ ).

Conclusions: Height is a determinant for evaluating blood pressure, and height ranges of $10 \mathrm{~cm}$ are more suitable for children and adolescents. The proposed percentiles based on height ranges allowed assessment of the DBP and SBP suggest their use in epidemiological and educational contexts.
\end{abstract}

Keywords: Blood pressure, Percentiles, Height, Children, Adolescentes

\section{Background}

Evaluation of blood pressure (BP) and the prevention of hypertension in children and adolescents has become a priority worldwide [1]. Thus, until a few years ago, their inclusion in clinical practice during physical examinations was unusual [2]. Actually, it is widely known that evaluating BP in children and adolescent populations was an important component, not only for the pediatric

\footnotetext{
* Correspondence: rossaunicamp@gmail.com

${ }^{1}$ Universidad Católica del Maule, Av San Miguel 3605, Talca, Chile Full list of author information is available at the end of the article
}

examination, but also for prevention in medical examinations [3].

Identifying children with high blood pressure is difficult to establish. This is especially the case since determining factors exist, such as age, sex, ethnicity, specific racial height groups $[4,5]$, socioeconomic conditions, and lifestyle [6], among other factors.

In this sense, a number of simple and easy to use tools have emerged in clinical practice for detecting high BP in children and adolescents [7]. Generally, these are based fundamentally on percentile tables [8].

(C) The Author(s). 2021 Open Access This article is licensed under a Creative Commons Attribution 4.0 International License, which permits use, sharing, adaptation, distribution and reproduction in any medium or format, as long as you give appropriate credit to the original author(s) and the source, provide a link to the Creative Commons licence, and indicate if changes were made. The images or other third party material in this article are included in the article's Creative Commons licence, unless indicated otherwise in a credit line to the material. If material is not included in the article's Creative Commons licence and your intended use is not permitted by statutory regulation or exceeds the permitted use, you will need to obtain permission directly from the copyright holder. To view a copy of this licence, visit http://creativecommons.org/licenses/by/4.0/ The Creative Commons Public Domain Dedication waiver (http://creativecommons.org/publicdomain/zero/1.0/) applies to the data made available in this article, unless otherwise stated in a credit line to the data. 
In fact, in their studies, some researchers have proposed references for diverse regions of the world. Some are based on the function of chronological age [1,9] and others by height $[2,3,10]$. Many of these are cumbersome and impractical for daily use. In addition, some even incorporate a variable other than age in the presentation of their standards [11]. This makes it difficult to quickly detect high BP in children and adolescents.

Therefore, in the presence of a variety of methods that allow identification of elevated levels of BP in children and adolescents, recent studies have demonstrated that the measurement of absolute height divided into height ranges of $5 \mathrm{~cm}$ [12] and $10 \mathrm{~cm} \mathrm{[13]} \mathrm{are} \mathrm{practical} \mathrm{tools}$ and useful in detecting high BP in children and adolescents. Thus, the methods based on chronological age and proposed formulas are better suited for tall children [8].

As a result, based on these premises, this study was guided by the following objectives: (a) identify height ranges $(5$ and $10 \mathrm{~cm}$ ) for detecting $\mathrm{BP}$ in children and adolescents better suited to students in the Maule Region and (b) propose percentiles for assessing BP based on age, sex, and absolute height. This information may be useful for researchers and health science professionals for developing specific strategies for the Maule Region.

\section{Methods}

\section{Type of study and sample}

A descriptive cross-sectional study was carried out with a sample of 3,013 students Chileans (Latinos - Latin Americans) between the ages of 5.0 and 18.9 years old. The simple population consisted of students from elementary and secondary municipal schools located in the Maule Region of Chile. The number of students in the study totaled 29,500 (17,410 males and 12,100 females). Probability proportional to size (PPS) sampling was used to select the sample. Stratified sampling proportional to the total number of students based on sex and age from the different schools was used to determine the final sample. Specifically, 12 schools were included, resulting in $10,2 \%$ [1832 (6.2\%) males and 1,181 (4.0\%) females] with a CI of $95 \%$.

The study was conducted according to the Declaration of Helsinki for Human Subjects. In addition, the research was approved by the Ethics Committee from the Universidad Autónoma de Chile (certificate number 2413). Parents or guardians approved the evaluation of their children by signing informed consent. The students themselves also provided written consent to participate.

Students of both sexes from municipal schools included in this study ranged in age from 5.0 to 18.9 years old. Students excluded from the research were those taking medication or with any type of illness and/or symptom of one during the previous month and those not completing the anthropometric examinations (weight and/or height).

\section{Procedures}

Data collection took place from March to August 2017. All evaluations were carried out in specified locations at each school (Department of Physical Education) during classes held from 8:00 a.m. to 12:00 noon, Monday to Friday. Prior to collecting information, each school was asked for permission to carry out the research. Based on the address, each school provided data, such as birth date, age, sex, and parent or guardian's name. Anthropometric evaluations and BP were collected by 2 experienced health professionals.

The anthropometric evaluations were carried out with the students barefoot, wearing shorts and a shirt as suggested and described by Ross and Marfell-Jones [14]. Body weight was measured with a digital scale (Tanita, United Kingdom, Ltd.) with a scale of $0-150 \mathrm{~kg}$ and an accuracy of $100 \mathrm{~g}$. Standing height was measured using a portable stadiometer (Seca \& Co. KG, Hamburg, Germany) with a precision of $0.1 \mathrm{~mm}$ and a scale of 0 $2.50 \mathrm{~m}$. After every 10 subjects, the scale was reset, and the stadiometer was recalibrated. Body Mass Index (BMI = weight/standing height) was calculated.

BP (diastolic DBP and systolic SBP) was recorded based on the recommendations of the American Academy of Pediatrics (AAP) [15]. Each subject sat on a chair with his or her back against the back of a chair with feet planted on the floor and the right arm (unclothed) extended on a table (at the height of the heart). BP was taken twice at 1 min intervals between measurements. A certified mercury sphygmomanometer (Omron M6) [16] was used to measure the BP.

The cut-off points for BP were adopted according to those proposed by the United States Department of Health and Human Services [17]: normotensive < p90; pre-hypertensive $\geq \mathrm{p} 90$ to $\mathrm{p} 95$; and hypertensive $\geq \mathrm{p} 95$. To evaluate $\mathrm{BP}$, height intervals based on age ranges were created and used according to those suggested by Banker et al. [12] and described by Chiolero et al. [5] in ranges of $5 \mathrm{~cm}$ and in ranges of $10 \mathrm{~cm}$. In addition, $108 \mathrm{~cm}$ was established as the minimum height with $188 \mathrm{~cm}$ as the maximum height for males, and for females, $98 \mathrm{~cm}$ was the minimum and $178 \mathrm{~cm}$ the maximum height.

\section{Statistical analysis}

Normalization of the data was carried out by using Kolmoronov Smirnov's method. Descriptive statistical mean $(\mathrm{X})$, standard deviation (SD), and ranges were used. Comparison of data between both sexes was carried out with a student t-test for independent samples. Pearson's correlations were used to analyze the relationship 
between DBP and SBP with height to categorize normotensive and hypertensive BP for both sexes and for height ranges of $5 \mathrm{~cm}$ and $10 \mathrm{~cm}$. In addition, the $\%$ of explication of $\mathrm{R}^{2}$ was calculated. For all cases, $p<0.05$ was adopted. These calculations were performed using SPSS 18.0. The LMS method was used based on three smoothed curves $[\mathrm{L}(\mathrm{t})$ Box-Cox transformation, $\mathrm{M}(\mathrm{t})$ median, and $\mathrm{S}(\mathrm{t})$ Coefficient of Variation] to create the percentiles [18]. For each sex, percentiles P50, P90, P95, and P97 were calculated for DBP and SBP for absolute height. LMS Chart Maker version 2.3 [19] was used to generate the curves.

\section{Results}

The anthropometric variables and BP reflected in the sample of children and adolescents from the Maule Region are illustrated in Table 1. No significant differences in weight and height occurred from age 5 to 14 years old. However, from 15 to 18 years old, males were heavier and taller than the females $(p<0.05)$. For BMI, the significant differences were found in both sexes $(p>0.05)$. For DBP, males presented higher values from age 7 to 12 years old $(p<0.05)$. However, for the remaining ages, the values were relatively similar for both sexes $(p>0.059)$. For SBP, males showed values significantly higher than the females at ages 8 and 9 years old, and 11 and 12 years old, and from 15 to 18 years old $(p<0.05)$.

The relationships between the DBP and SBP with height for each category classified for BP are shown in Table 2 . The values for $R$ and $R^{2}$ were relatively similar when aligned by BP category for $5 \mathrm{~cm}$ and $10 \mathrm{~cm}$.

Comparisons for BP adjusted for absolute height for ranges of 5 and $10 \mathrm{~cm}$ are depicted in Fig. 1. Significant differences occurred between both sexes when SBP and DBP were aligned by ranges of $5 \mathrm{~cm}$ : ranges 128 to $133 \mathrm{~cm}$; from 133 to $138 \mathrm{~cm}$; from 138 to $143 \mathrm{~cm}$; and from 143 to $148 \mathrm{~cm}(p<0.05)$. For the SBP, differences continued in height ranges: 158 to 163 and 168 to $173 \mathrm{~cm}(p<0.05)$. Furthermore, differences were observed in DBP in the range of 123 to $128 \mathrm{~cm}(p<0.05)$. For the $10 \mathrm{~cm}$ categories, differences emerged in DBP in the range of 138 to $148 \mathrm{~cm}(p<0.05)$ while in the SBP, the range was 158 to $168 \mathrm{~cm}(p<0.05)$.

Table 3 shows the percentiles distribution using the LMS method (p50, p90, p95, and p97) adjusted for height ranges of $10 \mathrm{~cm}$ for both sexes. The values for DBP and SBP increased as did the height ranges.

\section{Discussion}

The results from this study have shown slight to moderate positive correlations between height with DBP and SBP categories of normotensive and hypertensive BP. These correlations were relatively similar in the height ranges determined by 5 and $10 \mathrm{~cm}$. However, when comparing DBP and SBP by height range of $5 \mathrm{~cm}$ by sex, significant differences occurred in 4 height ranges (from 128 to $133 \mathrm{~cm} ; 133$ to $138 \mathrm{~cm} ; 138$ to $143 \mathrm{~cm}$; and from 143 to $148 \mathrm{~cm}$ ). In addition, significant differences were observed in the $10 \mathrm{~cm}$ range in only one of 138 to $148 \mathrm{~cm}$ in DBP and in SBP, height from 158 to $168 \mathrm{~cm}$.

As a result, based on the findings obtained, the results from this research demonstrated that the BP differs very little in the height ranges of $10 \mathrm{~cm}$. This appears to reflect a better suitability to evaluate DBP and SBP in children and adolescents in the Maule Region in relation to $5 \mathrm{~cm}$.

In fact, in the $10 \mathrm{~cm}$ ranges, children and adolescents from various ages were grouped together to fit into particular height ranges. This allowed correcting for slow and/or rapid growth rates among children and adolescents. Thus, at whatever age, height may vary, resulting to a large extent in the presence of a wider range of $\mathrm{BP}$ [12] values. Therefore, the use of $10 \mathrm{~cm}$ height intervals to evaluate BP may be an advantage over chronological age since it is widely known that during the stages of childhood and adolescence that children and adolescents experience important changes in body size and maturation during physical growth [20]. Thus, height would explain variability substantially more than age [21].

In this sense, height is a practical and accurate measure that serves to evaluate a variety of populations and diverse ethnic groups during the growth stage, especially when it is used in conjunction with evaluating BP [12, 22, 23]. Furthermore, it appears to be immanent that efforts are being made to correct and create simpler and more practical techniques and tools to better identify hypertension in children [24] and adolescents and incorporate height routinely into medical examinations.

A number of studies have reported that height is a non-invasive alternative that serves to analyze changes and/or thresholds of BP related to chronological age [21]. Also, height is considered as a useful indicator for doctors. The use of this anthropometric variable may contribute to identifying children and adolescents with elevated BP and, consequently, offer a possible treatment [8].

In fact, based on previous findings, the researchers developed percentiles for DBP and SBP based on $10 \mathrm{~cm}$ height ranges for children and adolescents of the Maule Region. In effect, the United States Department of Health and Human Services [17] maintains that the reference values for BP thresholds for children and adolescents need to meet the requisites for six variables: DBP, SBP, age, gender, weight, and percentile for height.

The proposed percentiles for this study meet the requirements indicated above. This tool may serve as a simple and easy to use alternative for early detection of pre- and hypertension in children and adolescents. It 
Table 1 Anthropometric characteristics of the children and adolescents studied

\begin{tabular}{|c|c|c|c|c|c|c|c|c|c|c|c|}
\hline \multirow{2}{*}{$\begin{array}{l}\text { Age } \\
\text { (years) }\end{array}$} & \multirow[b]{2}{*}{$\mathrm{n}$} & \multicolumn{2}{|c|}{ Weight (kg) } & \multicolumn{2}{|c|}{ Height $(\mathrm{cm})$} & \multicolumn{2}{|c|}{ BMI (kg/m2) } & \multicolumn{2}{|c|}{ DBP $(m m H g)$} & \multicolumn{2}{|c|}{ SBP $(\mathrm{mmHg})$} \\
\hline & & $x$ & SD & $\bar{x}$ & SD & $\bar{x}$ & SD & $x$ & SD & $x$ & SD \\
\hline \multicolumn{12}{|l|}{ Males } \\
\hline $5.0-5.9$ & 64 & 21.5 & 3.3 & 113.5 & 6.0 & 16.6 & 1.8 & 61.8 & 13.8 & 97.9 & 14.1 \\
\hline $6.0-6.9$ & 77 & 26.0 & 6.6 & 120.1 & 6.1 & 17.9 & 3.8 & 61.7 & 13.7 & 97.6 & 12.5 \\
\hline $7.0-7.9$ & 63 & 31.0 & 7.0 & 127.3 & 6.6 & 19.0 & 3.1 & $64.8^{*}$ & 11.7 & 101.7 & 14 \\
\hline $8.0-8.9$ & 77 & 32.2 & 6.5 & 130.4 & 5.3 & 18.8 & 2.9 & $63.8^{*}$ & 9.5 & $103.0^{*}$ & 13 \\
\hline $9.0-9.9$ & 96 & 36.8 & 8.8 & 136 & 8.3 & 19.8 & 3.8 & $66.9^{*}$ & 11.4 & $106.4^{*}$ & 14.5 \\
\hline $10.0-10.9$ & 92 & 42.1 & 9.8 & 142.4 & 7.1 & 20.6 & 3.5 & $67.3^{*}$ & 10.6 & 106.2 & 12.8 \\
\hline $11.0-11.9$ & 89 & 47.2 & 10.8 & 147.9 & 7.7 & 21.5 & 4.0 & $69.8^{*}$ & 13.3 & $109.2^{*}$ & 15.7 \\
\hline $12.0-12.9$ & 106 & 50.4 & 10.9 & 154.3 & 8.2 & 20.7 & 4.0 & $69.9^{*}$ & 11.2 & $110.7^{*}$ & 16.7 \\
\hline $13.0-13.9$ & 157 & 54.7 & 10.2 & 160.8 & 8.5 & 20.7 & 2.9 & 68.1 & 12.1 & 110.8 & 14 \\
\hline $14.0-14.9$ & 180 & 60.0 & 11.0 & 166.1 & 6.6 & 21.7 & 3.7 & 68.3 & 11.7 & 112 & 15 \\
\hline $15.0-15.9$ & 182 & $64.5^{*}$ & 9.2 & $169.9^{*}$ & 7.0 & 22.3 & 3.0 & 69.2 & 10.1 & $114.3^{*}$ & 14.8 \\
\hline $16.0-16.9$ & 214 & $70.4^{*}$ & 12.8 & $171.5^{*}$ & 7.1 & 23.9 & 4.1 & 70.9 & 10.5 & $117.4^{*}$ & 15.8 \\
\hline $17.0-17.9$ & 279 & $71.7^{*}$ & 13.3 & $171.4^{*}$ & 6.4 & 24.4 & 4.1 & 73.5 & 12.7 & $121.8^{*}$ & 19.3 \\
\hline $18.0-18.9$ & 156 & $71.6^{*}$ & 11.0 & $172.0^{*}$ & 6.9 & 24.2 & 3.6 & 71.2 & 12.3 & $119.7^{*}$ & 20.5 \\
\hline Total & 1832 & 56.1 & 19.2 & 157.4 & 19.5 & 21.9 & 4.2 & 69.1 & 12.1 & 112.5 & 17.5 \\
\hline \multicolumn{12}{|l|}{ Females } \\
\hline $5.0-5.9$ & 55 & 22.1 & 3.5 & 113.7 & 5.2 & 17.0 & 2.2 & 62.2 & 12.0 & 97.5 & 12.6 \\
\hline $6.0-6.9$ & 58 & 25.7 & 5.4 & 119.4 & 5.8 & 17.9 & 2.9 & 60.1 & 10.7 & 98.6 & 10.4 \\
\hline $7.0-7.9$ & 52 & 29.1 & 6.0 & 126.2 & 6.2 & 18.1 & 2.5 & 61.4 & 9.5 & 101.1 & 12.4 \\
\hline $8.0-8.9$ & 52 & 32.9 & 7.5 & 130.2 & 6.6 & 19.2 & 3.4 & 61.7 & 8.1 & 99.2 & 11.1 \\
\hline $9.0-9.9$ & 76 & 36.5 & 8.0 & 137.4 & 6.8 & 19.2 & 3.1 & 63.9 & 8.8 & 101.6 & 10.9 \\
\hline $10.0-10.9$ & 116 & 42.1 & 9.1 & 144.0 & 8.0 & 20.2 & 3.2 & 65.2 & 8.7 & 105.4 & 12.3 \\
\hline $11.0-11.9$ & 81 & 47.2 & 9.0 & 150.9 & 7.3 & 20.7 & 3.6 & 65.6 & 9.4 & 104.4 & 12.9 \\
\hline $12.0-12.9$ & 110 & 54.0 & 10.7 & 156.0 & 6.2 & 22.1 & 4.0 & 66.1 & 12.0 & 108 & 12.7 \\
\hline $13.0-13.9$ & 75 & 56.3 & 10.3 & 158.6 & 7.3 & 22.4 & 3.6 & 69.0 & 10.3 & 110.9 & 12.0 \\
\hline $14.0-14.9$ & 93 & 59.3 & 11.6 & 158.6 & 6.9 & 23.5 & 3.8 & 69.5 & 11.1 & 112.0 & 16.1 \\
\hline $15.0-15.9$ & 81 & 60.4 & 10.5 & 159.6 & 4.2 & 23.7 & 3.9 & 69.0 & 9.1 & 110.3 & 13.2 \\
\hline $16.0-16.9$ & 114 & 62.8 & 12.1 & 159.2 & 5.5 & 24.7 & 4.6 & 71.5 & 9.6 & 113.1 & 13.3 \\
\hline $17.0-17.9$ & 141 & 64.1 & 13.9 & 158.5 & 4.9 & 25.4 & 4.9 & 72.3 & 12.4 & 111.1 & 16.4 \\
\hline $18.0-18.9$ & 77 & 59.7 & 9.6 & 157.8 & 5.7 & 24 & 3.6 & 72.4 & 10.7 & 109.7 & 14.1 \\
\hline Total & 1181 & 50.5 & 17 & 149 & 15.6 & 22 & 4.6 & 67.4 & 11.1 & 107.3 & 14.2 \\
\hline
\end{tabular}

Legend: * significant difference in relation to women, $X$ Average, SD Standard deviation, BMI Body Mass Index, SBP Systolic blood pressure, DBP Diastolic blood pressure

Table 2 Relationship of height with BP by category in normotensive and hypertensive in children of both sexes

\begin{tabular}{|c|c|c|c|c|c|c|c|c|}
\hline \multirow[t]{3}{*}{ Categories } & \multicolumn{4}{|c|}{ Males } & \multicolumn{4}{|c|}{ Females } \\
\hline & \multicolumn{2}{|c|}{ DBP $(\mathrm{mmHg})$} & \multicolumn{2}{|c|}{ SBP $(m m H g)$} & \multicolumn{2}{|c|}{ DBP $(\mathrm{mmHg})$} & \multicolumn{2}{|c|}{ SBP $(\mathrm{mmHg})$} \\
\hline & $\bar{R}$ & $\mathrm{R}^{2}$ & $\bar{R}$ & $\mathrm{R}^{2}$ & $\mathrm{R}$ & $\mathrm{R}^{2}$ & $\bar{R}$ & $\mathrm{R}^{2}$ \\
\hline \multicolumn{9}{|l|}{$5 \mathrm{~cm}$ categories } \\
\hline Normotensive & 0.31 & 0.1 & 0.45 & 0.2 & 0.37 & 0.13 & 0.38 & 0.14 \\
\hline Hypertensive & 0.27 & 0.07 & 0.57 & 0.32 & 0.39 & 0.15 & 0.53 & 0.29 \\
\hline \multicolumn{9}{|l|}{$10 \mathrm{~cm}$ categories } \\
\hline Normotensive & 0.32 & 0.1 & 0.46 & 0.21 & 0.39 & 0.15 & 0.39 & 0.15 \\
\hline Hypertensive & 0.26 & 0.07 & 0.59 & 0.35 & 0.4 & 0.16 & 0.53 & 0.29 \\
\hline
\end{tabular}



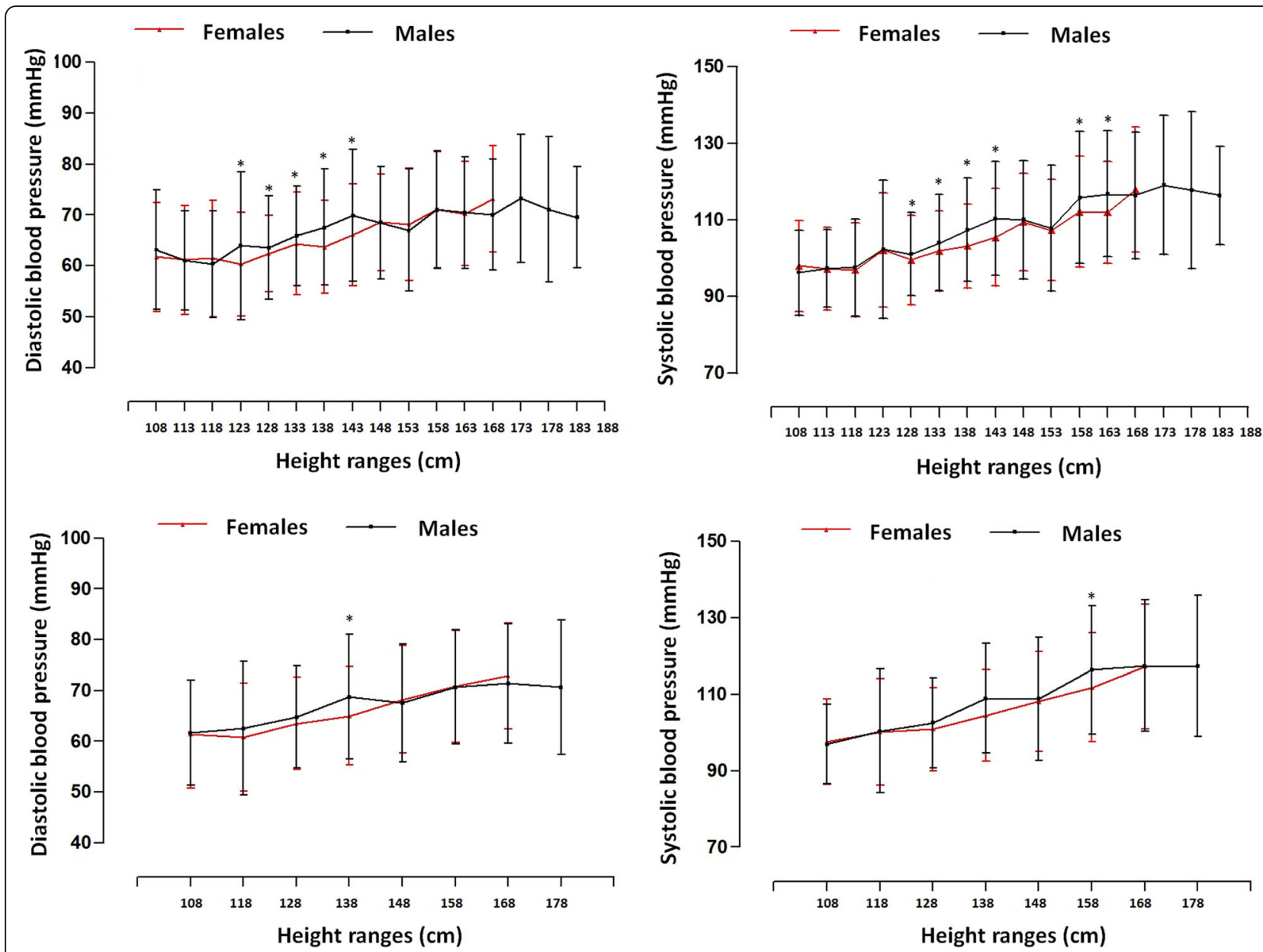

Fig. 1 Comparison of the mean and \pm SD values for Diastolic blood pressure and Systolic blood pressure by age ranges for both sexes (above $5 \mathrm{~cm}$ and below $10 \mathrm{~cm}$ )

may also be useful for professionals working in clinical and epidemiological contexts. In addition, it may have an important role in the prevention of cardiac [25] diseases during growth and development.

As a result, the cut-off points adopted for this research were those proposed in the fourth report of the US Department of Health and Human Services [17]: <p90 as normotensive; $\geq \mathrm{p} 90$ to $\mathrm{p} 95$ as pre-hypertensive; and $\geq$ p95 as hypertensive. These cut-off points determine limits and identify children and adolescents at greater risk of pediatric hypertension. The cut-off points also help identify individuals who need to have more examinations to control BP, including promoting preventative and healthy [2] lifestyles.

It is widely recognized that the reference standards for development for a specific population may not be applicable to other geographic regions. This is due to racial, ethnic, anthropometric, and cultural [26] differences.

In this sense, in a recent study carried out by other researchers [27], they determined that the students from the Maule Region reached adult height of $172.1 \pm 6.9 \mathrm{~cm}$ for males and $159.8 \pm 5.7 \mathrm{~cm}$ for females. In fact, these values correspond to a height range of the percentiles proposed here of $168-178 \mathrm{~cm}$ for males with a BP of $139.9 / 86.6 \mathrm{mmHg}$ and for females, a height range of $158-168 \mathrm{~cm}$ with a corresponding BP of 130.4/ $84.8 \mathrm{mmHg}$. These values at 18 years old are close to the limits of $140 / 90 \mathrm{mmHg}$ used for adults, coinciding with the values obtained in the present study.

Future studies need to evaluate not only height ranges, but also they need to explore ranges for weight, BMI, waist circumference, and among other anthropometric variables. Furthermore, it is necessary to develop longitudinal studies since height growth varies ostensibly, especially during the transition from childhood to adolescence.

As a result, despite the limitations highlighted here, this research has some strengths. For example, the probability selection of the sample makes it possible to generalize the results to other contexts with similar characteristics. In addition, we proposed the availability for professionals and researchers of an online electronic 
Table 3 Distribution of percentiles to assess DBP and SBP in children and adolescents adjusted for absolute height and sex

\begin{tabular}{|c|c|c|c|c|c|c|c|c|c|c|c|c|c|c|}
\hline \multirow{2}{*}{$\begin{array}{l}\text { Height } \\
\text { ranges (cm) }\end{array}$} & \multicolumn{7}{|c|}{$\mathrm{DBP}(\mathrm{mmHg})$} & \multicolumn{7}{|c|}{ SBP $(\mathrm{mmHg})$} \\
\hline & $\mathrm{L}$ & $M$ & $S$ & P50 & P90 & P95 & P97 & $\mathrm{L}$ & $M$ & $S$ & P50 & P90 & P95 & P97 \\
\hline \multicolumn{15}{|l|}{ Males } \\
\hline 108-117.9 & -0.64 & 60.3 & 0.18 & 60.3 & 77.6 & 84 & 88.7 & -0.26 & 97 & 0.13 & 97 & 115.1 & 121.1 & 125.1 \\
\hline $118-127.9$ & -0.44 & 61.6 & 0.18 & 61.6 & 78.1 & 83.9 & 88 & -0.09 & 99.1 & 0.13 & 99.1 & 117.4 & 123.2 & 127.2 \\
\hline $128-237.9$ & -0.28 & 64 & 0.17 & 64 & 80.1 & 85.5 & 89.4 & 0 & 102.6 & 0.13 & 102.6 & 121.3 & 127.2 & 131.2 \\
\hline $138-147.9$ & -0.16 & 66.3 & 0.17 & 66.3 & 82.3 & 87.6 & 91.3 & -0.04 & 106.5 & 0.13 & 106.5 & 126.2 & 132.5 & 136.7 \\
\hline $148-157.9$ & -0.09 & 68 & 0.16 & 68 & 83.8 & 89 & 92.6 & -0.19 & 110.1 & 0.13 & 110.1 & 131.1 & 137.9 & 142.6 \\
\hline $158-167.9$ & -0.01 & 69.6 & 0.16 & 69.6 & 85.6 & 90.8 & 94.3 & -0.34 & 114.1 & 0.14 & 114.1 & 136.8 & 144.3 & 149.5 \\
\hline 168-177.9 & 0.07 & 70.4 & 0.16 & 70.4 & 86.6 & 91.8 & 95.3 & -0.27 & 116.1 & 0.14 & 116.1 & 139.9 & 147.8 & 153.2 \\
\hline 178-187.9 & 0.11 & 70.4 & 0.17 & 70.4 & 86.8 & 92 & 95.5 & -0.07 & 117.1 & 0.15 & 117.1 & 141.7 & 149.7 & 155.1 \\
\hline$>188$ & 0.14 & 70.5 & 0.17 & 70.5 & 87 & 92.2 & 95.8 & 0.14 & 118.4 & 0.15 & 118.4 & 143.7 & 151.7 & 157.1 \\
\hline \multicolumn{15}{|l|}{ Females } \\
\hline $98-107.9$ & -0.33 & 56.9 & 0.19 & 56.9 & 73 & 78.7 & 82.6 & 1.4 & 95.3 & 0.13 & 95.3 & 110.5 & 114.6 & 117.3 \\
\hline $108-117.9$ & -0.31 & 59.1 & 0.17 & 59.1 & 74.4 & 79.7 & 83.4 & 1.34 & 97.7 & 0.13 & 97.7 & 113.2 & 117.4 & 120.2 \\
\hline $118-127.9$ & -0.27 & 60.5 & 0.16 & 60.5 & 75 & 79.8 & 83.2 & 1.18 & 99.7 & 0.12 & 99.7 & 115.3 & 119.7 & 122.5 \\
\hline $128-237.9$ & -0.1 & 62.4 & 0.15 & 62.4 & 76.2 & 80.7 & 83.7 & 0.92 & 101.5 & 0.12 & 101.5 & 117.3 & 121.8 & 124.8 \\
\hline $138-147.9$ & 0.14 & 64.8 & 0.15 & 64.8 & 78.3 & 82.5 & 85.4 & 0.59 & 104.2 & 0.12 & 104.2 & 120.7 & 125.5 & 128.7 \\
\hline 148-157.9 & 0.25 & 67.6 & 0.15 & 67.6 & 81.6 & 85.9 & 88.8 & 0.34 & 107.5 & 0.12 & 107.5 & 125.2 & 130.5 & 134 \\
\hline $158-167.9$ & 0.08 & 70.1 & 0.15 & 70.1 & 84.8 & 89.5 & 92.7 & 0.2 & 111.2 & 0.13 & 111.2 & 130.4 & 136.3 & 140.2 \\
\hline 168-177.9 & -0.15 & 72.3 & 0.15 & 72.3 & 87.8 & 92.8 & 96.3 & 0.02 & 115.9 & 0.13 & 115.9 & 137.1 & 143.8 & 148.3 \\
\hline$>178$ & -0.39 & 74.4 & 0.15 & 74.4 & 90.6 & 96 & 99.8 & -0.16 & 121.1 & 0.14 & 121.1 & 144.6 & 152.2 & 157.4 \\
\hline
\end{tabular}

Legend: $M$ medium, $L$ Box-Cox transformation, $S$ coefficient of variation, $P$ percentile, $S B P$ systolic blood pressure, $D B P$ diastolic blood pressure

calculator system for evaluating BP by height ranges. The graphic reports provided by the calculations could significantly facilitate BP evaluations. The calculator may be obtained online with the following link: http://www. reidebihu.net/pad_pas_ch.php.

\section{Conclusions}

In conclusion, the researchers identifies that height is a determinant for evaluating $\mathrm{BP}$, and the height ranges for $10 \mathrm{~cm}$ are better suited for children and adolescents of the Maule Region. BP in the $10 \mathrm{~cm}$ height ranges differs very little from those of $5 \mathrm{~cm}$. In light of these results, percentiles were proposed for evaluating DBP and SBP based on height ranges and sex. This information is useful for identifying children and adolescents with elevated $\mathrm{BP}$ and needs to be included in routine clinical examinations and in the educational system.

\section{Abbreviations}

BP: Blood pressure; DBP: Diastolic blood pressure; SBP: Systolic blood pressure; BMI: Body Mass Index; AAP: American Academy of Pediatrics

\section{Acknowledgements}

We would like to express our gratitude to all the participating students, teachers, and schools for their tremendous support.

\section{Authors' contributions}

M.C.B., R.G.C. and W.C.B. contributed to the design of the research study. R.G.C., M.C.B., R.V.E., J.S.T., and F.C.C. collected data, contributed to the discussion, wrote the manuscript and reviewed/edited the manuscript. C.L.A translated, edited, commented on, and reviewed the manuscript. M.C.B., R.G.C., C.U.A., R.V.E., and F.C.C. collected and analyzed data and/or reviewed/ edited the manuscript. R.G.C., and M.C.B. provided statistical analyses and reviewed/edited the manuscript. All authors revised and agreed on the views expressed in the manuscript.

\section{Funding}

Fondecyt Regular 1141295, Chile.

\section{Availability of data and materials}

The datasets supporting the conclusions of this research article are available by emailing the corresponding author.

Ethics approval and consent to participate

The study protocol was approved by the Ethic Committee of the Universidad Autónoma de Chile, UA 238/2014. Parents and guardians provided informed written consent for their children under the age of 16 participating in the study. In addition, all students under and over the age of 16 in the study provided written informed consent acknowledging their consent to participate and their understanding of the research procedures and objectives.

\section{Consent for publication}

Not applicable.

\section{Competing interests}

The authors declare that they have no competing interests. 


\section{Author details}

${ }^{1}$ Universidad Católica del Maule, Av San Miguel 3605, Talca, Chile. ${ }^{2}$ Universidad Católica Silva Henríquez, Santiago, Chile. ${ }^{3}$ Universidad del Bío Bío, Chillán, Chile. ${ }^{4}$ Universidad Nacional de San Agustín de Arequipa, Arequipa, Perú. ${ }^{5}$ Universidad Privada San Juan Bautista, Lima, Perú. ${ }^{6}$ Centro de Investigación CINEMAROS, Arequipa, Perú. 'Escuela de Kinesiología, Facultad de Salud, Universidad Santo Tomás, Talca, Chile.

Received: 7 August 2020 Accepted: 26 December 2020

Published online: 08 January 2021

\section{References}

1. Al Salloum AA, El Mouzan MI, Al Herbish AS, Al Omar AA, Qurashi MM. Blood pressure standards for Saudi children and adolescents. Ann Saudi Med. 2009;29(3):173-8.

2. Barba G, Buck C, Bammann K, Hadjigeorgiou C, Hebestreit A, Mårild S, Molnar D, Russo P, Veidebaum T, Vyncke K, Ahrens W. Blood pressure reference values for European non-overweight school children: the IDEFICS study. Int J Obes (Lond). 2014;38(S2):48.

3. Krzyżaniak A, Krzywińska-Wiewiorowska M, Stawińska-Witoszyńska B, Kaczmarek M, Krzych L, Kowalska M, Szilágyi-Pągowska I, Palczewska I, Karch A, Jośko J, Ostrowska-Nawarycz L. Blood pressure references for Polish children and adolescents. Eur J Pediatr. 2009;168(11):1335-42.

4. Lurbe E, Cifkova R, Cruickshank JK, Dillon MJ, Ferreira I, Invitti C, Kuznetsova T, Laurent S, Mancia G, Morales-Olivas F, Rascher W. Management of high blood pressure in children and adolescents: recommendations of the European Society of Hypertension. J Hypertens. 2009;27(9):1719-42.

5. Chiolero A, Bovet P, Paradis G. Screening for elevated blood pressure in children and adolescents: a critical appraisal. JAMA Pediatr. 2013;167(3):26673.

6. Hvidt KN, Olsen MH, Ibsen $\mathrm{H}$, Holm JC. Effect of changes in BMI and waist circumference on ambulatory blood pressure in obese children and adolescents. J Hypertens. 2014;32(7):1470-7.

7. Chiolero A, Paradis G. User-friendly tools to identify elevated blood pressure in children. Paediatr Child Health. 2013;18(2):63-4.

8. Ma C, Kelishadi R, Hong YM, Bovet P, Khadilkar A, Nawarycz T, KrzywińskaWiewiorowska M, Aounallah-Skhiri H, Zong XN, Motlagh ME, Kim HS Performance of eleven simplified methods for the identification of elevated blood pressure in children and adolescents. Hypertension. 2016;68(3):61420.

9. Rosner B, Cook NR, Daniels S, Falkner B. Childhood blood pressure trends and risk factors for high blood pressure: the NHANES experience 19882008. Hypertension. 2013;62(2):247-54.

10. Neuhauser HK, Thamm M, Ellert U, Hense HW, Rosario AS. Blood pressure percentiles by age and height from nonoverweight children and adolescents in Germany. Pediatrics. 2011;127(4):e978-88.

11. Park MK, Menard SW, Schoolfield J. Oscillometric blood pressure standards for children. Pediatr Cardiol. 2005;26(5):601.

12. Banker A, Bell C, Gupta-Malhotra M, Samuels J. Blood pressure percentile charts to identify high or low blood pressure in children. BMC Pediatr. 2016; 16(1):98.

13. Chiolero A, Paradis G, Simonetti GD, Bovet P. Absolute height-specific thresholds to identify elevated blood pressure in children.J Hypertens. 2013;31(6):1170-4.

14. Ross WD. Kinanthropometry. Physiological testing of the high-performance athlete. 1991.

15. Flynn JT, Kaelber DC, Baker-Smith CM, et al. Clinical Practice Guideline for Screening and Management of High Blood Pressure in Children and Adolescents. Pediatrics. 2017;140(3):e20171904.

16. Topouchian JA, El Assaad MA, Orobinskaia LV, El Feghali RN, Asmar RG. Validation of two automatic devices for self-measurement of blood pressure according to the International Protocol of the European Society of Hypertension: the Omron M6 (HEM-7001-E) and the Omron R7 (HEM 637IT). Blood Press Monit. 2006;11(3):165-71.

17. U.S. Department of Health and Human Services. The fourth report on the diagnosis, evaluation, and treatment of high blood pressure in children and adolescents. Pediatrics. 2004;114(2):555-76. (suppl, 4th report).

18. Cole TJ, Bellizzi MC, Flegal KM, Dietz WH. Establishing a standard definition for child overweight and obesity worldwide: international survey. BMJ. 2000; 320(7244):1240.
19. Pan H, Cole TJ. Chartmaker LMS. Available online at: http://www. healthforallchildren.co.uk (accessed March 28, 2015). 2006.

20. Gomez-Campos R, Arruda M, Luarte-Rocha C, Urra Albornoz C, Almonacid Fierro A, Cossio-Bolaños M. Enfoque teórico del crecimiento físico de niños y adolescentes. Rev Española de Nutr Hum Diet. 2016;20(3):244-53.

21. Daniels SR, McMahon RP, Obarzanek E, Waclawiw MA, Similo SL, Biro FM, et al. Longitudinal correlates of change in blood pressure in adolescent girls. Hypertension. 1998;31(1):97-103.

22. Lu Q, Ma CM, Yin FZ, Liu BW, Lou DH, Liu XL. How to simplify the diagnostic criteria of hypertension in adolescents. J Hum Hypertens. 2011; 25(3):159.

23. Galescu O, George M, Basetty S, Predescu I, Mongia A, Ten S, Bhangoo A. Blood pressure over height ratios: simple and accurate method of detecting elevated blood pressure in children. International Journal of Pediatrics. 2012 8:2012: 253497.

24. Mitchell CK, Theriot JA, Sayat JG, Muchant DG, Franco SM. A simplified table improves the recognition of paediatric hypertension. J Paediatr Child Health. 2011;47(1-2):22-6.

25. Mattace-Raso FU, van der Cammen TJ, Hofman A, van Popele NM, Bos ML, Schalekamp MA, Asmar R, Reneman RS, Hoeks AP, Breteler MM, Witteman $J C$. Arterial stiffness and risk of coronary heart disease and stroke. Circulation. 2006;113(5):657-63.

26. Goonasekera CD, Dillon MJ. Measurement and interpretation of blood pressure. Arch Dis Child. 2000;82(3):261-5.

27. Gomez-Campos R, Arruda M, Leite-Portella D, Pacheco-Carrillo J, UrralAlbornoz C, Sulla-Torres J, Luarte-Rocha C, Cossio-Bolaños MA. Physical growth and body adiposity curves in students of the Maule Region (Chile). Front Pead. 2019;7:323.

\section{Publisher's Note}

Springer Nature remains neutral with regard to jurisdictional claims in published maps and institutional affiliations.

Ready to submit your research? Choose BMC and benefit from:

- fast, convenient online submission

- thorough peer review by experienced researchers in your field

- rapid publication on acceptance

- support for research data, including large and complex data types

- gold Open Access which fosters wider collaboration and increased citations

- maximum visibility for your research: over $100 \mathrm{M}$ website views per year

At BMC, research is always in progress.

Learn more biomedcentral.com/submissions 